\title{
O TÉCNICO DE ESCOLARIDADE MÉDIA NO SETOR PRODUTIVO: SEU NOVO LUGAR E SUAS COMPETENNCIAS
}

\author{
JoÃo Bosco LaUdARES* \\ AntôNio ToMAsi*
}

RE SU M 0: O s convênios recentes estabelecidos entre os Centros de Formação Profissional e as grandes indústrias empregadoras de profissionais técnicos, de nível médio, parecem indicar uma realocação desses profissionais na estrutura de produção. A posição intermediária, entre os operários e os engenheiros ou entre o "chão de fabrica" e o "escritório de projeto", típica da gestão taylorista, tende ao desaparecimento na gestão horizontalizada dos novos modelos organizacionais. A proximidade desses profissionais com os engenheiros passa a demandar deles um nível mais elevado de qualificação, como atesta 0 aumento da demanda dos setores produtivos industriais de tecnólogos, profissionais de nível superior. Recorre-se à sociologia do trabalho e às noções construídas por ela, de qualificação, de competência e de saber, como forma de se identificar as tendências de mobilidade profissional dos técnicos e dos tecnólogos no interior de grandes empresas industriais.

Palavras-chave: Técnico. Tecnólogo. Q ualificação.

\section{THE SECONDARY SCHOOL TECHNICIAN IN THE PRODUCTIVE SECTOR: HISNEWPLACE AND COMPETENCES}

A BSTRA CT : The recent agreements between the Professional Training Centers (at high-school levels) and large industries suggest a new position is given to these professionals in the production structure.

* Doutor em História e Filosofia da Educação pela Puc-SP e professor do Mestrado em Tecnologia do Centro Federal de Educação Tecnológica de Minas G erais (CEFET-MG).

E-mail: matematica@ pucminas.br

* Doutor em Sociologia pela Universidade de Paris VII e professor do Mestrado em Tecnologia do Centro Federal de Educação Tecnológica de Minas G erais (CEFET-MG).

E-mail: tomasi@uai.com.br

E duc. Soc., Campinas, vol. 24, n. 85, p. 1237-1256, dezembro 2003

Disponível em <http:/ / www.cedes.unicamp.br> 
Their intermediate position between workers and engineers or between "the factory floor" and the "planning department", typical of taylorism, tends to disappear from the horizontal management of the new organizational models. This leads them to need higher levels of qualification, closer to those of engineers, which is proved by the increasing demand of technologists, professionals of superior level, in the productive sector. D rawing on Sociology of Work and its notions of qualification, competence and knowledge, we seek to identify the tendencies of professional mobility of both technicians and technologists in large industries.

Key words: Technician. Technologist. Qualification.

\section{Introdução}

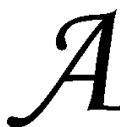

s empresas têm, tradicionalmente, se organizado numa estrutura hierárquica vertical, ao longo da qual os trabalhadores se distribuem e se distinguem segundo as suas qualificações. $\mathrm{Na}$ indústria, na base do "chão de fábrica", encontra-se o operário, responsável direto pelas operações, cuja capacitação se limita à do saberfazer. Nos setores intermediários são alocados os técnicos, de escolaridade média. Junto destes, encontram-se os tecnólogos, profissionais especialistas em determinadas áreas de exigência de tecnologias intensivas e específicas num campo estreito de domínio técnico. Os dois últimos são, de modo geral, originários das escolas técnicas e dos Centros Superiores de Educação da rede federal de formação profissional, os CEFETS. A cima destes, encontram-se os técnicos, encarregados da coordenação técnica ou da gerência de serviços e de produção.

Com a chamada reestruturação produtiva estabelece-se uma nova configuração no cenário industrial, que diz respeito às novas tecnologias, seja na mudança da base técnica (máquinas, energia, informatização produtiva), seja na mudança dos modelos de organização e de gestão do trabalho (taylorismo, toyotismo). A tarefa, atividade essencialmente taylorizada, passa a ser cumprida em sistemas integrados ganhando na dimensão flexível e polivalente da produção uma denominação diferenciada - função - , parâmetro dos sistemas pós-taylorizados. As mudanças no sentido de uma horizontalização da gestão, da redução das hierarquias, deslocam o trabalhador do seu posto de trabalho para o exercício de uma função, ou seja, para o exercício de um conjunto de atividades múltiplas. A adaptação à nova configuração da fábrica flexível, global, informa- 
tizada, mais tecnicizada, não apenas define um novo lugar para 0 trabalhador como demanda, a partir daí, que sejam repensados os programas de formação e de qualificação profissionais.

Essa categoria de trabalho, resultado da nova divisão operacional, retrata a reestruturação organizativa, não mais segregada em departamentos isolados ou em postos de trabalho claramente delimitados. Tal fato teria produzido um alargamento das funções dos trabalhadores com implicações tanto no seu saber quanto no lugar que deverão ocupar na nova estrutura.

Assim, o técnico, profissionalmente reconhecido pela posição hierárquica intermediária, elemento de controle e de articulação na relação entre o escritório de projetos e a oficina, ou seja, entre plano e operação, e, ainda, pela sua qualificação, como detentor de parte dos conhecimentos teóricos e práticos da produção industrial, tem seu lugar redefinido e seu saber colocado em questão.

A partir deste contexto, duas questões se colocam e exigem, pelo seu imbricamento, que sejam tratadas simultaneamente: 1) Se os setores intermediários da produção industrial tendem a desaparecer, qual deve ser o lugar reservado aos técnicos na nova estrutura? 2) Se não ocupam mais os mesmos lugares, que novos saberes são a eles demandados?

Tais questões colocam-se no centro das preocupações atuais relativas aos programas de formação profissional e nas proposições curriculares da educação tecnológica. Ou seja, elas relacionam as competências demandadas aos técnicos pelos setores produtivos industriais, aos programas de formação, de qualificação/ requalificação, dos centros de formação profissional. Parece-nos inevitável, portanto, o recurso à sociologia do trabalho, na qual os conceitos de qualificação/ requalificação e de competência, bem como o debate acerca da presença dessas noções no meio empresarial e acadêmico, ocupam importante espaço.

\section{D a qualificação à competência}

0 maior desafio, hoje, dos trabalhadores e dos centros de formação profissional diz respeito às demandas por competência. A qualificação, que, durante décadas, definiu os programas de formação e os processos de recrutamento e de seleção de pessoal das em- 
presas, não se mostra mais, no entendimento de alguns, sobretudo dos empresários, adequada às atuais transformações do mundo do trabalho, exigindo-se dos trabalhadores um novo perfil profissional.

Segundo esses entendimentos, tais demandas seriam impostas pelo acelerado desenvolvimento tecnológico fundado, particularmente, na informática, e pelo desenvolvimento de novos modelos organizacionais. Ambos teriam como papel primordial procurar controlar um sistema de produção, descrito por Dadoy (1990) como desestabilizado, ou seja, um sistema de produção pressionado por um mercado sem fronteiras, cada vez mais exigente, e sujeito a uma concorrência cada vez maior.

$\mathrm{N}$ a verdade, constrangimentos sociais expressos nos mercados de trabalho e na configuração das suas novas relações de força, anteriores às inovações tecnológicas e organizacionais, explicariam tais demandas.

Esses mesmos entendimentos permitem, em contrapartida, explicar as demandas a partir de transformações sociais mais amplas cujo impacto poderia ser percebido nos indivíduos e na construção das suas mentalidades. $\mathrm{O}$, ainda, na emergência de um novo modelo de apreensão da realidade social.

Essas perspectivas se dividiriam, portanto, entre as idéias de que as demandas por competência expressariam, de um lado, uma evolução natural, uma continuidade do mundo taylorizado, naturalizado, com o qual aprendemos a conviver ao longo dos últimos séculos, e, de outro lado, uma ruptura com esse mundo.

Muito embora essas idéias apareçam de maneira mais forte em alguns autores dedicados ao estudo da questão do que em outros, elas não são, no estágio atual de desenvolvimento, suficientes para distingui-los.

Tanto as inovações tecnológicas quanto as organizacionais marcaram o final do século XX, sobretudo as duas últimas décadas, e parecem figurar, também, de maneira importante no calendário do mundo do trabalho no século que se inicia.

Não nos parece difícil, portanto, perceber que as inovações organizacionais e tecnológicas não são muito diferentes daquelas ocorridas na metade do século passado com o desenvolvimento e o avanço da automatização e do taylorismo. Tal período marca, inclusive, a ori- 
gem da sociologia do trabalho francesa e tem importante contribuição nos trabalhos de Friedmann (1946) e, em seguida, nos de Naville (1961), autores considerados os pais da disciplina. Eles não hesitaram em desmontar, cada um à sua maneira, esses fatos. Os debates travados entre os dois vão se constituir significativa referência teórica e histórica para todos aqueles que procuram compreender 0 mundo do trabalho e suas transformações.

Sabemos que os novos modelos organizacionais se colocam em substituição ao modelo taylorista, cujo esgotamento vem sendo assinalado desde meados da década de 1970. A partir desse período, uma nova ordem econômico-financeira internacional é redefinida trazendo sérios danos à autonomia dos Estados Nacionais. Os desdobramentos de tais fatos podem ser medidos, hoje, no impacto da chamada mundialização da economia, particularmente sobre a vida econômica dos países subdesenvolvidos ou em desenvolvimento.

Sabemos, igualmente, que, se o estado atual do desenvolvimento tecnológico não pode ser considerado nem uma continuidade à maquinização ou à automação que despontaram nos séculos X IX e $\mathrm{XX}$, nem uma ruptura definitiva com estas, delas se destaca pela enorme rapidez que tem implementado aos processos produtivos e de informação. Acrescente-se que semelhante rapidez pode ser vista, inclusive, nas transformações ocorridas, nesse mesmo período, nos modos de vida e de consumo da sociedade.

D a mesma forma, é inegável que as atividades de trabalho não são mais as mesmas de décadas anteriores. 0 trabalho, a partir de então, desmaterializa-se, perde substância, e contribui para desfazer as fronteiras, até então precisas, entre produtor e consumidor. Invade e homogeneíza o cotidiano do trabalhador e do cidadão.

Neste sentido, o trabalho que produzia coisas agora produz sociedade (Touraine, 1994). Precisamente, o trabalho não pode ser considerado apenas execução de papéis profissionais. Diferente de ser uma das manifestações de uma cultura ou de um sistema de normas sociais, ele produz a sociedade na medida em que, como nos ensina Touraine (1994, p. XV), ele “(...) é e permanece historicamente 0 instrumento da ruptura decisiva com a imagem da sociedade como uma civilização ou uma concepção do mundo, portanto, como um conjunto de valores, de normas e de formas de organização". 0 trabalho é, definitivamente, um instrumento de transformação do mundo. 
Continuando, se os referidos períodos guardam alguma semelhança, as iniciativas para compreendê-los não têm que ser necessariamente as mesmas, ainda que esses autores tenham certamente importante contribuição a nos dar. Em outras palavras, mesmo que a questão posta por Friedmann (1962), em meados do século passado, sobre 0 futuro dos jovens trabalhadores e suas qualificações em face das transformações tecnológicas, pareça ganhar, novamente, sentido, haveremos de encontrar outros caminhos além dos muros dos determinismos tecnológico e social que marcaram os debates de então.

Se novos perfis são demandados aos trabalhadores, pode ser equivocado acreditar que tal fato se deve às inovações tecnológicas e organizacionais ou aos constrangimentos sociais (mercado, relações de força) que revestem as inserções das inovações no mundo do trabalho. A parentemente é esta a direção que a literatura e os estudiosos da questão parecem tomar (Stroobants, 1994; Dadoy, 1990; Schwartz, 1997; Zarifian, 1995; entre outros). Talvez porque não queiram repetir os erros do passado, talvez porque as demandas por competência e a noção mesma de competência nos empurrem para caminhos diferentes porque, finalmente, haveria algo de intrinsecamente novo nelas.

Se alguns trabalhadores e/ ou setores produtivos podem, ainda, colocar-se à margem das referidas transformações, certamente os engenheiros, técnicos e profissionais ligados, particularmente, à produção industrial não se encontram entre eles. Habituados a verem associados à sua profissão as idéias de progresso, de produção, de precisão, entre outras, eles se vêem, agora, confrontados com o que se convencionou chamar de novos paradigmas do mundo do trabalho.

Se somos levados a crer, a partir dos discursos que freqüentam tanto o mundo do trabalho como o da academia, que as chamadas inovações tecnológicas e organizacionais transformaram o mundo do trabalho e passaram, então, a demandar um novo trabalhador, tais discursos permitem-nos, implicitamente, pensar que talvez não precisemos de um novo trabalhador, mas apenas reconhecer nele as qualidades que até então não víamos (D adoy, 1990). Assim, mais importante do que compreender as transformações que a inserção de novas tecnologias nos aportariam, seria pensar que os modelos utilizados de compreensão do mundo do trabalho, constrangidos pelas demandas sociais, dão mostras de esgotamento. 
A compreensão do desafio que se coloca, hoje, a esses trabalhadores e aos centros de formação profissional não se constitui, para os estudiosos da questão, uma tarefa simples. São inúmeros os recortes sociais e sociológicos, técnicos, políticos, econômicos, ideológicos, entre outros, que contribuem para a complexidade do problema. Portanto, não se pode ter a ambição de esgotá-la, muito especialmente nas poucas páginas que seguem, sem correr o risco de se perder na sua complexidade. Assim, poderíamos acrescentar outras questões àquelas já postas, como: Por que as demandas por competências devem reconstruir os perfis profissionais dos nossos técnicos? $\mathrm{Ou}$, ainda, redefinir os programas dos nossos centros de formação profissional? A reforma implementada no ensino técnico, de escolaridade de nível médio, ao desintegrar o currículo nas Escolas Técnicas - separação da formação geral e formação técnica e modularização dos conteúdos - vem atender que tipo de perfil profissional? Trata-se simplesmente de uma organização curricular visando à redução de custos da gestão acadêmica? Q ue feições devem tomar estes novos perfis? Por quê? Q ue fatores se destacam na sua construção? A resposta a todas estas questões exige que se percorra um caminho muito preciso, por vezes estabelecido a partir de outras questões: 0 que entendemos por competência? Que elementos a constituiriam? Quem a define? E, finalmente, qual o papel do desemprego na importância dada, atualmente, à noção de competência? Qual o papel da ideologia na sua constituição?

\section{A noção de qualificação}

As questões atuais relativas à globalização dos mercados e da produção, no que diz respeito às novas competências dos trabalhadores, exigem que sejam reconstruídas no plano teórico. Se as demandas por competência podem traduzir as transformações ocorridas, hoje, no mundo do trabalho, como compreendê-la sem recorrermos à noção de qualificação?

Embora os estudos sobre a qualificação possam ocorrer em muitas partes do mundo e em diferentes momentos, eles adquirem maior consistência na França, sobretudo a partir da Segunda Guerra Mundial, motivados pelas demandas sociais relativas à modernização do setor produtivo e pela intensificação do taylorismo naquele país. 
Inicialmente, a qualificação encontra-se esboçada em G eorge Friedmann (1946), na sua obra Problèmes humains du machinisme industriel. Melhor delineada em obras subseqüentes, ela tem o seu estatuto oficial reconhecido por Touraine (1955) e Naville (1961), nos estudos sobre os sistemas de trabalho e sobre a automação, respectivamente. A noção de qualificação, portanto, constrói-se no interior da sociologia, a partir destes autores e de muitos outros que os seguiram, o que a torna uma noção essencialmente sociológica.

A construção desse conceito, todavia, não se mostrou nem tem se mostrado, até os dias de hoje, uma tarefa fácil. Inicialmente, a qualificação emerge a partir de duas perspectivas divergentes que se sobressaem. A primeira delas, friedmanniana, identificada também como substancialista, é centrada no saber e no saber-fazer adquiridos no trabalho e na aprendizagem sistemática. Relacionam-se, portanto, o tipo de intervenção exigida pelo posto e as exigências de qualificação. O avanço tecnológico era inevitável, pensava Friedmann (1962), e levaria a uma desqualificação do trabalhador, ou seja, a uma transferência da sua qualificação para o posto de trabalho, tese que Touraine (1955) confirma em seu estudo sobre os sistemas de trabalho. Para Friedmann (1962), o trabalho artesanal era a forma completa do trabalho qualificado, ou seja, a atividade intelectual é um elemento constitutivo importante da qualificação que pode ser observada na relação estreita entre a complexidade de uma tarefa ou de um conjunto de tarefas e as capacidades apresentadas pelo trabalhador. Mas se o desenvolvimento tecnológico produziria, por um lado, uma massa de trabalhadores desqualificados, empobrecidos, expropriados do seu único capital, ou seja, o saber, a automação, passo seguinte do maquinismo, produziria também trabalhadores qualificados, o que poderia ser entendido como um retorno ao artesanato. Encontrava-se aí esboçada a tese de Freissenet (1977), sobre desqualificação e superqualificação.

Na segunda perspectiva, desenvolvida por Naville (1963), também conhecida como relativista, a qualificação é o resultado de um processo de formação autônomo, independente da formação espontânea no trabalho. A qualificação é o saber e 0 saber-fazer do trabalhador. Ela é relativa e suas formas dependem do estado de forças produtivas e das estruturas socioeconômicas nas quais os trabalhadores se inserem. Ela se construiria a partir, muito mais, de critéri- 
os sociais, em que as relações de força e os conflitos têm um papel importante, do que individuais. Ou seja, contrariando Friedmann (1962), a qualificação não se reduz às qualidades intrínsecas ao indivíduo (suas habilidades ou seu saber-fazer). Pesquisas desenvolvidas por Naville (1963) contrariam, ainda, a idéia de superqualificação e desqualificação. A qualificação, para esse autor, não é uma substância encontrada no indivíduo, mas uma relação, um lugar de encontro de inúmeros fatores.

Se as tentativas de se construir uma noção de qualificação não parecem dirigir-se para um consenso, o que fica claro pelo menos nas primeiras tentativas, a literatura sociológica pode, ao longo dos últimos 50 anos, testemunhar a convergência de alguns elementos como, por exemplo, a constatação de que a qualificação determina as grades hierárquicas e salariais nas relações de trabalho. $\mathrm{Ou}$, ainda, de que se trata de uma noção em aberto, ou seja, em permanente processo de construção, isso porque a noção de trabalho, sobre a qual ela se constrói, está em permanente evolução.

É, pois, uma noção cambiante e altamente flexível na medida em que trabalho e educação são noções polissêmicas e estatutos constituintes da noção de qualificação, a qual se constrói, hoje, a partir da formação escolar, passando pela qualificação em serviço e pela requalificação. Esta última por meio da experiência e da atuação profissional complementada com programas de educação continuada na integração escola-empresa.

Entretanto, percebe-se que as tentativas dos autores franceses de construção da noção de qualificação não apenas ocorrem no momento de desenvolvimento do taylorismo, mas são por ele influenciadas, o que nos permite dizer que a qualificação tem o taylorismo como referência.

\section{D a qualificação à competência}

A exemplo da noção de qualificação, a de competência emerge em um momento de crise econômica que produz profundas transformações no aparelho de produção e nas políticas de mãode-obra. G lobaliza-se a economia, internacionalizam-se e transformam-se os mercados, desenvolve-se a terceirização que impõe aos técnicos a necessidade de se desenvolver novas competências volta- 
das para a gestão da produção, a qualidade do produto e para 0 estabelecimento de relações profissionais.

Então, se ao técnico, de escolaridade média, era imposta uma atuação definida pelo taylorismo na intermediação da concepção à execução, agora com a fábrica global se contempla não só a interação produtor e cliente, mas também o trabalho em equipe. A horizontalização produtiva, com eliminação de funções intermediárias pela integração e flexibilização de tarefas, exige capacitação diferenciada do técnico, a partir de saber-fazer-técnico e de saber-fazer-relacional no trato de questões originadas não somente da fabricação, mas dos setores de compras, de marketing, do comercial, como da engenharia de produto e de processos.

Q ue elementos motivariam a construção desta nova noção? Ou, que tipo de transformação estaria ocorrendo no mundo do trabalho que implicaria tão profunda transformação do sistema de produção e de trabalho?

As primeiras tentativas para se explicar as transformações recorrem à velha receita do determinismo tecnológico, nomeando, dessa vez, a informática como a responsável pelo surgimento da demanda das novas competências. Estudos desenvolvidos acerca dessas demandas mostram, entretanto, que elas estariam presentes, também, em setores que não fazem uso da informática.

Entre os esforços para se encontrar uma resposta muitos autores, entre eles Dadoy (1990), parecem concordar que, com o "fim do taylorismo", teria ocorrido uma desestabilização do processo de produção, o que teria levado a um grande número de disfunções imprevistas. Assim, as dificuldades para reestabilizar o sistema teriam levado o gerenciamento a se interessar pela formação do pessoal e pela designação de novas competências.

D iferente, então, da qualificação, a competência não teria 0 taylorismo como referência, mas os novos modos de organização de trabalho. Se, para alguns, tal passagem é entendida como um salto, uma ruptura de modelos, para outros, mais críticos ao modelo da competência, ela não seria outra coisa senão uma reatualização da qualificação. D eve-se ressaltar, contudo, que a apropriação da noção de competência por diferentes segmentos sociais parece inevitável e, neste sentido, ela não parece diferente da noção de qualificação. 
Mas, se o olhar, quase que geral, é para essas transformações no mundo do trabalho, na tentativa de se compreender os novos paradigmas do trabalho no pós-taylorismo, ainda existe espaço para que algumas questões sejam, também, postas: Podemos falar realmente do fim do taylorismo? O que habituamos chamar de novos modos de organização não seriam, na verdade, um neotaylorismo? Se os novos modos de organização são uma realidade, eles seriam uma realidade para todos os setores produtivos? De fato, predominam as pesquisas feitas em grandes empresas. Muitas vezes, empresas que se colocam na vanguarda tecnológica e organizacional, suportando ou implementando grande pressão na concorrência e que, muito embora possam ter, em função desses fatores, maior visibilidade, ocupam uma importância relativa no mercado de trabalho. Sabemos que grande parte dos empregos, mesmo de técnicos, é criada em empresas de menor porte, muitas vezes distantes dos avanços tecnológicos e organizacionais, ou ainda das demandas de mercado, muito embora de alguma forma possam ser atingidas por muitos dos problemas que atingem as grandes. Pouco se sabe sobre as empresas de menor porte. Q ue tipo de gerência praticam? Como se defrontam com os problemas de qualidade? Se superaram 0 taylorismo, que alternativas têm encontrado? Q uais são os seus paradigmas de trabalho e de produção?

Seria importante ainda que fossem feitas duas observações. A primeira delas diz respeito ao fato de que nossas observações retratam 0 momento atual que é o de transformação. 0 que nos assegura que este momento não seria apenas de transição? $\mathrm{O}$ u que, tão logo os sistemas de trabalho se estabilizem, o técnico teria nele um outro lugar no sistema de produção? A segunda diz respeito aos antigos sistemas de produção taylorista. 0 que nos assegura que as competências que exigimos hoje, dos técnicos, já não estavam presentes antes quando predominava o sistema de produção taylorista, e que, simplesmente, não eram reconhecidas? Isto é, o não-reconhecimento das competências do técnico no setor produtivo não se fazia em razão da natureza do taylorismo, o qual intrinsecamente é um modelo limitado, altamente formatado e prescritivo, que restringe uma atuação mais flexível e versátil? O u melhor, o taylorismo era um inibidor das competências do trabalhador?

Mesmo que a importância da competência seja, na prática, limitada pelos fatos acima expostos, sua importância amplia-se na me- 
dida mesma em que consegue monopolizar os debates atuais sobre as transformações do mundo do trabalho, constituindo-se em um elemento analisador do momento atual.

\section{A noção de competência}

Nas últimas duas décadas, sobretudo na anterior, a noção de competência vem ocupando progressivamente o debate na literatura sociológica e no "chão de fábrica". Ela foi colocada pelos empresários, empregadores, traduzindo a preocupação com as novas exigências dos postos de trabalho e suscitando inúmeras questões. Q ue transformaçõ̃es estariam ocorrendo que exigiriam uma nova noção? A emergência da noção de competência assinala o fim da noção de qualificação? Não poderia haver uma coexistência das noções? Não seria um modismo? A noção de competência estaria relacionada ao desenvolvimento tecnológico e organizacional que caracterizara as últimas três décadas? $\mathrm{O} u$, ainda, qual o papel do desemprego, que tem marcado essas últimas décadas do século, no surgimento e no uso do termo competência?

Ao longo destes quase 20 anos, muitos foram os que se debruçaram sobre essas questões, com olhos e ouvidos voltados para as inquietações do "chão de fábrica" e para as formulações teóricas. Com a ajuda de pesquisas, procuram preencher este grande mosaico na necessidade de se construir a noção de competência.

0 termo competência tem origem, possivelmente, nos meios jurídicos e em nenhum momento ele foi de uso popular porque uma certa competência é exigida para julgar a competência de alguém (Isambert-Jamati, 1994). A partir dos anos de 1970, ele aparece na literatura sociológica e educacional, mas de forma polissêmica, e só a partir de meados dos anos de 1980 ele adquire 0 sentido conhecido atualmente. Para essa autora, a competência no singular pertence à linguagem jurídica, ao passo que no plural comporta uma marca, um encontro positivo em um mesmo homem de qualidades (competências possuídas). Elas, continua a autora, são únicas e pertencem a uma categoria formalizada, ou seja, não podem ser encontradas em todos os indivíduos. Isso significa dizer que a competência não se confundiria com 0 talento que pertenceria aos artistas, ou seja, ela não é uma característica individual. 
A noção de competência está, portanto, associada à execução de tarefas complexas, organizadas e que exigem uma atividade intelectual importante. E essas tarefas são realizadas por especialistas. 0 trabalhador competente não é necessariamente aquele que cria as técnicas, mas aquele que as utiliza adequadamente e está apto a adaptá-las às novas situações de trabalho.

A noção de competência, todavia, não apenas se impõe de fora para dentro da sociologia do trabalho como exige que outros saberes compartilhem da tentativa de construção da noção. Entre esses saberes se destacam os relativos à cognição. Em outras palavras, é o próprio saber que se apresenta como essencial na análise, muito embora ele não seja objeto de estudo da sociologia do trabalho.

As competências são relativas porque dependem da maneira como são vistas, mas elas são, também, "reais". Elas podem ser caracterizadas por tipo de saber (o saber-fazer e seus recortes específicos, saber + um verbo que denote ação). Esses saberes se definem em oposição aos saberes escolares e são adquiridos no trabalho. 0 conhecimento, portanto, está relacionado à situação profissional (Stroobants, 1994).

As tentativas de se construir a noção de competência apontam muito mais para 0 artesão que para 0 assalariado como referência do trabalhador. A formação que deve acontecer no trabalho, junto com a organização, parece automaticamente "qualificante". Os conhecimentos adquiridos no trabalho não são transmissíveis pela formação escolar. A questão parece ser não do conteúdo das competências, mas da mobilização destas, que seria feita por meio dos "saberes, saber-fazer e saber-ser".

A demanda das empresas por competências está menos ligada às novas tecnologias e mais ligada aos novos imperativos da produção, sobretudo os da qualidade. D a mesma forma, as mudanças variam segundo os setores e as empresas estudadas, o que contraria qualquer entendimento determinista.

As mudanças, portanto, apontam para um aumento das exigências dos níveis de saber, para uma descompartimentação das "especializações profissionais", para uma intelectualização do trabalho, para tarefas mais complexas, para a polivalência, para uma ampliação da autonomia. Ou seja, é menos um conhecimento intrinsecamente novo e mais uma descompartimentação dos saberes (D adoy, 1990). 
Diferentemente do trabalhador taylorizado, passivo, ele é agora um ator. $\mathrm{G}$ anham forma as exigências relativas ao comportamento. Concluindo, a competência é uma demanda do patronato, prioriza 0 trabalho, define-se pelo posto de trabalho, é medida pelo desempenho do trabalhador e só pode ser avaliada nele.

O custo social desta nova condição do trabalhador não parece, todavia, pequeno. Os críticos do chamado modelo das competências alertam, com razão, para o fato de que a competência, na medida em que tem como referência 0 indivíduo, suas habilidades e talentos e não mais 0 coletivo de trabalho, suas certificações, diplomas, conspiraria contra a solidariedade até então assegurada pela qualificação. Os saberes, previamente certificados, não mais tornam iguais os trabalhadores que, ao verem valorizadas as suas habilidades, capacidades únicas, individuais, reconhecem-se diferentes. A referência no indivíduo reconfigura a relação capital/ trabalho e, com a mesma força, coloca em xeque a organização dos trabalhadores e suas representações.

A competência é um campo de conhecimento partilhado com outras disciplinas e profissionais: psicólogos, antropólogos, ergonomistas, lingüistas, educadores. A competência encontra-se, também, e sobretudo, nos comportamentos, nas atitudes, que têm como característica fundamental não a solução de problemas, mas anteciparse a eles (Zarifian, 1995).

\section{O s trabalhadores e a construção de nova mentalidade}

Parece haver, há algum tempo, um consenso generalizado de que vivemos numa era de incerteza. E ela seria suficientemente relevante para se colocar como a mais importante referência para os sistemas de produção e de formação. Talvez, contrariando tal consenso, 0 melhor mesmo seria dizer que sempre vivemos em uma era de incerteza, mas que só agora começamos a construir um olhar, um modelo de análise, capaz de compreender tal fato. Seja como for, este consenso, que acompanha os mais diferentes discursos sobre o mundo atual e as perspectivas de futuro, aparece associado à demanda de um novo perfil dos trabalhadores.

O taylorismo, que invadiu o mundo do trabalho a partir de Princípios da administração científica (Taylor, 1963), parecia, aos olhos dos técnicos, uma continuidade "natural", embora quase dois séculos 
depois de A riqueza das nacooes (Smith, 1983), onde a divisão do trabalho é pela primeira vez descrita e exposta aos mundos acadêmico e empresarial. Esta última obra, por sua vez, formatada nos mais claros princípios da ciência natural, via na decomposição dos fenômenos da natureza um modo de observá-la, descrevê-la, compará-la, explicá-la, apreendê-la, dominá-la e, sobretudo, reconstituí-la. As possibilidades de predição, de controle, de experimentação, oferecidas por tal modelo e, ainda, as idéias de certeza e de precisão, ou mesmo de tempo e de ritmo, por ele permitidas, contribuíram, sem duvida, para a construção, ao longo dos últimos séculos, da mentalidade dos técnicos. É interessante constatar que, não obstante as descobertas no campo das ciências naturais, muito especialmente da física, pudessem colocar em questão tal modelo, essa mentalidade insistiu em se manter e se reproduzir.

Novos paradigmas são, portanto, colocados no mundo do trabalho. 0 sociólogo e economista francês Zarifian (1995) recorre à noção de operação como sendo a que melhor traduz tal mentalidade. Produzir, para ele, "pode ser resumido, de maneira simples, em uma sucessão de operaçóes elementares, que se encadeiam umas às outras" (Zarifian, 1995, p. 9).

Para Zarifian (1995), a operação inspira-se em um modelo físico. Está inscrita em um processo pré-descritível, previsível, regular e regulado. Ela é um átomo do movimento. É uma forma de apreender e de compreender a realidade, fundada em processos sociais que gastaram quase dois séculos para se desenvolver e se consolidar.

O conceito de operação está ligado à destruição de um modo de vida preexistente, sobretudo o modo de vida rural e doméstico. Ele diz, ainda, sobre a separação do trabalho daquele que 0 efetua. 0 trabalho torna-se forma objetivada, ou seja, pode ser descrito, estruturado, organizado, independente daquele da pessoa que o realiza. Ele não mais se refere à pessoa que trabalha, mas ao posto de trabalho. D essa forma, a operação carece do surgimento de uma população operária de maneira permanente e obrigada a vender a sua força de trabalho.

Para evitar qualquer equívoco, Zarifian (1995) observa que, na verdade, o trabalho, antes de poder ser dimensionado fisicamente, é o resultado de uma imposição social que permite falar de trabalho independentemente de quem trabalha. 
Assim, construída a mentalidade dos técnicos, ao longo dos tempos, em torno da noção de operação, ela deve, agora, refazer-se a partir dos évenements, ou seja, dos acontecimentos (Zarifian, 1995).

0 acontecimento, para Zarifian, ao contrário, constitui-se em uma outra forma de apreender a realidade. Ele não é um átomo do movimento, mas uma descontinuidade dele. Ele se instala como uma ruptura do desenvolvimento regular de um fenômeno ao qual damos importância. Ele se traduz pela pane. A pane cuja causa se desconhece.

Zarifian (1995) ensina-nos que o acontecimento é singular porque surge como uma coisa que não estava presente. E como se fosse um acréscimo de presença. Ele não pertence à situação porque se encontra fora das normas que descrevem e avaliam a situação. Mas, quando se produz, ele se encontra na situação.

O acontecimento é imprevisível porque surge no tempo e pára 0 movimento. 0 acontecimento é importante porque ele não pode ser reduzido a um fato do mundo objetivo. Somos nós, do mundo social, que fazemos do acontecimento um acontecimento. Em outras palavras, uma pane não terá nenhuma importância se nós não lhe dermos importância.

0 acontecimento é sempre interno à situação e, neste sentido, ele a ela pertence. Se um acontecimento se dá na relação entre dois serviços de uma empresa, por exemplo, para apreendê-lo será necessário apreender a situação formada por esses dois serviços. Assim, ele não pode ser compreendido como um efeito que se dá no meio, mas na situação.

Assim, a mentalidade dos técnicos, que estava habituada à operação, deve agora considerar o acontecimento. Se estavam habituados à certeza, devem, agora, levar em conta a incerteza. Cabe aos centros de formação profissional construir em seus novos profissionais um novo olhar, novas capacidades, sobretudo sociais, sem os quais eles se arriscam a não mais apreender e controlar o mundo que os cerca.

O termo "competência" tem surgido, nos mundos do trabalho e acadêmico, como a palavra-chave para o acesso ao que se acredita ser a nova realidade. A qualificação, até então moeda corrente do mundo do trabalho, condição necessária para 0 acesso ao mercado de trabalho, para o reconhecimento e a ascensão social, parece não mais gozar do mesmo prestígio. 


\section{D o novo lugar dos técnicos e de suas competências}

Se tomarmos como referência o tipo de demandas que, há algum tempo, são dirigidas às Escolas Técnicas Federais e aos Centros Federais de Educação Tecnológica, escolas-modelo no desenvolvimento da educacão profissional e de programas centrados na competência do trabalhador, constataremos que importantes mudanças vêm sendo conduzidas no sentido de redefinir o perfil profissional desses trabalhadores.

A reforma no ensino técnico médio que se faz hoje, acompanhada de grandes dificuldades, faz parte de um redirecionamento das políticas de formação profissional dos técnicos. Além do nível médio, a atenção das autoridades está também voltada para os níveis superiores de formação técnica. Certamente, a motivação do redirecionamento encontra-se no mercado de trabalho do técnico, cada vez mais exigente.

Os centros de formação profissional, capitaneados pelas Escolas Técnicas Federais - nível de escolaridade médio, pressionados por estas exigências e ao reconhecerem sua validade - , tentam dar resposta às demandas atuais buscando uma elevação na sua atuação ao evoluir, institucionalmente, para um Centro Federal de Educação Tecnológica, de nível acadêmico superior. Tal movimento foi denominado, dentro do Sistema Nacional de E ducação Tecnológica, de "cefetização". A formação ampliada e generalista do técnico complementa-se e aprofunda-se, especializando-se em áreas novas da tecnologia com o curso superior de tecnologia.

Aparentemente, o nível médio de formação não mais atende a indústria. Alguns Centros Federais de Educação Tecnológica, como o do Paraná, ampliaram suas vagas para o curso superior de tecnologia ao mesmo tempo em que diminuíram as do curso técnico. Em Minas Gerais, o CEFET, em convênio com uma grande montadora de automóveis, prepara-se para atender a demanda da empresa de requalificar 2 mil dos seus técnicos. Pretende-se, ao final de um período de formação sistemática, embora de duração inferior à dos cursos de engenharia, elevá-los a categorias profissionais de nível superior, no caso, de tecnólogos. 0 currículo do curso, centrado em tecnologias intensivas e especializadas, deverá garantir o novo perfil do trabalhador.

D e fato, tais demandas parecem sinalizar que a flexibilidade e a integração produtiva, práticas na nova gestão e organização do trabalho industrial, ao horizontalizarem a estrutura de produção, eli- 
minam o espaço do técnico, intermediário no processo de produção, e deslocam-no em direção ora dos operários, nas intervenções, ora em direção aos engenheiros, nas concepções, o que torna difusa a sua atuação na fábrica. E a proximidade com estes últimos, participando das tomadas de decisão, implícitas na aproximação, que redefine 0 perfil do novo trabalhador, o tecnólogo.

O s projetos pedagógicos em curso, atualmente, nas Escolas Técnicas Federais e nos Centros de Educação Tecnológica encontram-se, portanto, em reestruturação. De um lado a preocupação dos agentes formadores volta-se para a formação generalista dos técnicos, centrada em determinadas tecnologias especializadas, reforçando, assim, a importância do ensino superior técnico. De outro lado, a preocupação mostra-se com a aplicação tecnológica nas equipes de trabalho, o que exige que se desenvolva, nos jovens, os saberes sociais necessários ao exercício de suas novas atividades. As novas competências a serem construídas são, portanto, o grande desafio. Afinal, que competências são requeridas dos jovens técnicos? Em outras palavras, o acontecimento (Zarifian, 1995), que melhor traduz os problemas atuais da produção industrial, coloca em curso um processo de reconstrução da mentalidade dos jovens técnicos e tecnólogos.

Recebido em maio de 2003 e aprovado em agosto de 2003.

\section{Referências bibliográficas}

COSTE, M.; PICHAULT, F. Traité de sociologie du travail. Bruxelles: D e-Boeck Université, 1994. p. 169-196.

DADOY, M. La notion de qualification chez G eorge Friedmann. Sociologique du Travail, Paris, Dunod, v. 29, n. 1, p. 15-34, 1987.

DAD OY, M. La codification du travail et de l'emploi, face aux transformations des sytèmes de prodution. In: LA SO CIO L OG IE du travail et la codification du social. Toulouse: Université de Toulouse Le Mirail, 1990. v.1, p. 195-226.

FREISSENET, M. La division capitaliste du travail. Paris: Savelli, 1977. 
FRIED MANN, G. Introduction et méthodologie. In: Fried MANN, G.; Naville, P. Traité de sociologie du travail. Paris: A. Colin, 1962.

FRIED MANN, G. Problèmes humains du machinisme industriel. Paris: G allimard, 1963, c1946. 432p.

FRIED MANN, G. Le travail en miettes. Paris: Gallimard, 1972, c1956. 374p.

ISAMBERT-JAMATI, V. L'appel à la notion de compétence dans la Revue L'0 rientation Scolaire et Professionnelle à naissance et aujourd'hui. In: Rope, F.; TANG UY, L. Savoirs et compétences. Paris: L'Harmattan, 1994. p. 199-146.

NAVILLE, P. E ssai sur la qualification du travail. Paris: Marcel Rivière, 1956. 148p.

NAVILLE, P. A utomation et travail humain. Paris: CNRS, 1961. 741

NAVILLE, P. V ers l'automatisme social. Paris: Gallimard, 1963. 259 p.

RO LLE, P. Travail et salariat. Grenoble: Presses Universitaires de Grenoble, 1988. v.1

RO PE, F.; TANG UY, L. Savoirs et compétences: de l'usage de ces notions dans l'école et l'entreprise. Paris: L'Harmattan, 1994. 243p.

SCHWARTZ, Y. (O rg.). Reconnaissances du travail pour une approche ergologique. Paris: Puf, 1997.

SMITH, A. A riqueza das nações. São Paulo: Abril Cultural, 1983.

ST RO O BANTS, M. La visibilité des compétences. In: RoPE, F.; TANG UY, L. Savoirs et compétences. Paris: L'Harmattan, 1994. p. 175204.

TAYLOR, F. W. Princípios da administração científica. São Paulo: Atlas, 1963.

TOMASI, A. P.N. Qualificação ou competência? E ducação e Tecnologia, Belo Horizonte, v. 7, n. 1, p. 51-61, jan./ jun. 2002.

TO URAINE, A. L'évolution du travail ouvrier aux usines Renault. Paris: CNRS, 1955. 169p. 
TO URAine, A. Prefácio. In: Coste, M.; Pichault, F. Traité de sociologie du travail. Bruxelles: De-Boeck Université, 1994. p. XV.

TROUVE, P. L'évolution des agents de maîtrise face à la modernisation industrielle. Clermont Ferrand: Centre d'Études et de Recherches CRACEREQ, 1993. 432p

ZARIFIAN, P. L e travail et l'événement. Paris: L'Harmattan, 1995. 249p. 